\title{
BAQUIANO, UN ENIGMA CON HISTORIA
}

\author{
María Elvira Sagarzazu*
}

\section{ETIMOLOGÍA, LUGAR DE ORIGEN Y DIFUSIÓN GEOGRÁFICA}

Sostiene Corominas que baquiano procede de baqīya, voz que en árabe significa "el resto, lo que queda", y que con tal significado aparece usada en 1555 por Fernández de Oviedo ${ }^{1}$ (Historia general y natural de Indias). La obra había sido comenzada en 1534. Entre ambas fechas, Gutiérrez de Santa Clara también emplea baquiano en $1544^{2}$. Juan de Guzmán da cuenta de ella en 1586, creyéndola propia de Santo Domingo ${ }^{3}$. El Padre Acosta, en 1590, la anota como procedente de Cuba y Haití ${ }^{4}$ El Inca Garcilaso dice que se usaba en las islas de Barlovento ${ }^{5}$.

De lo anterior se desprende una primera conclusión, y es que el término empieza a difundirse en la región del Caribe, precisamente donde comenzara la colonización española. Otro dato a tener presente es que ni Corominas ni los demás autores citados lo consideran indígena, hecho que orienta nuestra atención hacia quiénes pudieron haber introducido en América una palabra que no formaba parte del castellano empleado por la mayoría de los españoles en el siglo XVI.

Por otro lado, no pervivió esta voz en los territorios caribeños con el vigor que alcanzó -y que conserva- en Venezuela y en el Río de la Plata ${ }^{6}$, por lo que intentaremos explicar qué factores pudieron haber contribuido a la difusión

\footnotetext{
* Escritora e investigadora. Argentina.

1. J. COROMINAS y J.A. PASCUAL, Diccionario crítico etimológico castellano e hispánico, $3^{\mathrm{a}}$. reimpresión, vol. I, Madrid, 1991, p. 493.

2. Ibidem.

3. Ibidem.

4. Ibídem.

5. Ibídem.

6. Ibídem.
} 
alcanzada en estas tierras. Como no ha sido posible incluir también a Venezuela en el presente trabajo, cuanto va a exponerse aquí en relación a baquiano corresponde a testimonios recogidos en la región cisplatina.

\section{LOS TRANSMISORES DEL CASTELLANO A AMÉRICA Y "LOS QUE SE QUEDARON"}

De los colonizadores venidos de España, sabido es que el grupo más numeroso procedió de Andalucía ${ }^{7}$, la región cuyo pasado nombre, Al Andalus, fue el dado por los árabes a todo el territorio peninsular conquistado por ellos a partir de 711.

Tanto en Argentina como en Venezuela, se denomina baquianos a los conocedores del terreno en que realizan sus actividades. Son peones a quienes su propio modo de vida, rural, obliga a desplazarse de un lado a otro, arreando ganado, guiándolo hacia otras estancias, o conduciéndolo con cualquier otro objeto hacia destinos a veces muy alejados del sitio donde se asienta normalmente el rodeo.

Una idea de la experiencia propia del baquiano surge del relato de la penúltima expedición del botánico Aimé Bonpland. Este médico y naturalista francés, que de joven había cuidado los jardines de la emperatriz Josefina en la Malmaison, pasó la mayor parte de su vida y murió en 1858 en Santa Ana, provincia de Corrientes (Argentina). A mediados del siglo XIX, ya octogenario, Bonpland no pudo sustraerse a la tentación de atravesar el enorme estado brasileño de Rio Grande do Sul con un baquiano encargado de trasladar cuatrocientas ovejas hacia una estancia riograndense ${ }^{8}$. El interés de Bonpland en acompañar al baquiano residió en que a lo largo del trayecto iba a poder recoger ejemplares de la flora nativa de un territorio jamás pisado por un naturalista. El baquiano podría guiarlo por sendas no solo desconocidas por los científicos sino también fuera de las picadas abiertas, tiempo atrás, por los jesuitas que tenían asentadas en la zona sus Misiones de Guaraníes, desde fines del siglo XVI hasta su expulsión a mediados del XVIII.

Más o menos por los mismos años de aquella penúltima aventura de Bonpland, un argentino ilustre, polígrafo, gran viajero y luego presidente de la nación, Domingo F. Sarmiento, también valora el quehacer del baquiano y lo describe como "el gaucho grave y reservado que conoce a palmo veinte mil leguas

7. P. BOYD-BOWMAN, «La procedencia de los españoles de América. 1540- 1559», Historia Mexicana, vol. XVII: 1, México, 1967, pp. 37-71 (p. 58).

8. Ph. Foucault, El pescador de orquídeas. Aimé Bonpland (1773-1858), Trad. José Federico Delos, Buenos Aires, 1994, p. 129. 
cuadradas de llanuras, montañas, bosques. Es el topógrafo más completo, el único mapa que lleva un general para dirigir los movimientos de su campaña"

Ahora bien, este sentido de conocedor práctico, de guía, que la voz conlleva, no guarda aparente relación con la raíz árabe que apunta al remanente de algo; ha de hilarse más fino para llegar al punto donde el significado del étimo árabe empalma con el de conocedor. Personalizando la idea de remanente y expresándola como los que quedan, se visualiza el recorrido de las nociones que contribuyeron a la génesis semántica de la voz, ya que ese remanente hace referencia a una presencia humana sometida a la acción del tiempo como condición necesaria para adquirir experiencia del terreno. La palabra resume la conexión existente entre permanecer en un lugar y llegar a conocerlo, exactamente lo que convierte a un peón en baquiano.

El término refleja, pues, una realidad, cual era que, entre los colonizadores españoles que quedaban de la primera hora, se encontraban algunos que habían alcanzado un particular dominio del hábitat en que residían. De esto y de las fechas en que aparece el vocablo escrito, se infiere que los primeros baquianos fueron españoles- y aquí español no alude a origen étnico o cultural sino al hecho de venir de España-. Y ha de tratarse de un español afincado desde el principio de la conquista, de los que no regresó a la metrópoli, como lo hacían otros que, por curiosidad o necesidad momentánea, probaban suerte en América pero tras algún desengaño regresaban a su patria.

El hecho de que exista un ejemplar humano determinado a permanecer en las colonias cualquiera fueran las condiciones imperantes en ellas, dice lo suyo a propósito del carácter o la urgencia del candidato. Los mejor dispuestos a tolerar los inconvenientes de la vida en las colonias serían aquellos cuyo presente tampoco era fácil en España. Afirma Domínguez Ortiz ${ }^{10}$ que venir a América "para el europeo normal se presentaba como una empresa muy costosa y arriesgada, que sólo intentarían aventureros, perseguidos políticos y religiosos y otras categorías excepcionales".

La adversidad económica suele vencerse con alguna facilidad, basta dar con un nicho laboral, descubriendo las oportunidades rentables o exitosas de cada época. Las condiciones sociales adversas, sin embargo, pueden ser consecuencia de varios factores y no se superan fácilmente, cuando no requieren, para ser superadas, cambios de actitud que a menudo afectan a más de un aspecto de la existencia, tal como les ocurre a los desplazados sociales por el motivo que sea.

9. J.M. SAROBE, «El gaucho guerrero», en G. TABOADA (ant.) Gauchos, Buenos Aires, 1992, pp. 4950.

10. A. Domínguez Ortiz, La sociedad americana y la corona española en el siglo XVII, Madrid, 1996, p. 25. 


\section{SITUACIÓN SOCIAL DE LOS MORISCOS}

Son conocidas las condiciones en que quedó la comunidad musulmana española a partir de 1502 y del edicto restrictivo de 1526 dictado contra ella por Carlos V. En la España de aquel siglo y el siguiente, los moriscos resultaron la minoría más perjudicada a medida que iba haciéndose efectivo el cumplimiento de las medidas que ponían fin al estatuto jurídico que había regulado la vida de sus antepasados, garantizándoles la práctica del islam y demás tradiciones comunitarias. Los procesos de la Inquisición española muestran que se dirigen particularmente contra los moriscos tras la nueva legislación, tanto que, entre 1569 y 1621, a esa minoría pertenece la mayoría de los encausados por el tribunal, 1.758 judaizantes frente a 9.354 moriscos $^{11}$.

La cancelación jurídica de la comunidad musulmana no significó la desaparición total de sus miembros sino su conversión, exilio o emigración hacia otros territorios. La huida tuvo como destinos preferidos -de quienes se mantuvieron en la fe tradicional-al Norte de África y algunos puntos de la Turquía otomana. Poco se ha investigado, en cambio, el éxodo por goteo de los otros moriscos mejor cristianizados, que regresaron a España un tiempo después de su expulsión ${ }^{12}$ y casi nada se sabe de los que vinieron a América no por motivos religiosos sino para superar el estigma social de descender de prohibidos. Para averiguar sobre ellos, hay que tener en cuenta que, por tratarse de gente culturalmente fronteriza, "les strategies dévelopées par les morisques sont ici comme là les mèmes. A part pour quelques récalcitrants, l'attachement à la foi islamique n'est pas tenace. Confinés très souvant à des tâches serviles, pour des périodes parfois longues, ils son ouvertes à toute opportunité"13. Iniciar una nueva vida en las colonias españolas de América significaba una opción que difícilmente pasaría inadvertida a los moriscos, tanto menos cuando sabido es que fue conducta frecuentemente seguida por la otra minoría perseguida, los criptojudíos. De ellos sí hay más noticias debido a su intervención en el comercio novomundano ${ }^{14}$, lo que a su vez atraería el interés de la Inquisición sobre ellos. El tribunal de Lima entre 1570 y 1600 procesó a 78 criptojudíos y sólo a dos moriscos ${ }^{15}$. El panorama no parece haber sido muy diferente en el virreinato de

11. B. EsCANDELl BONET, «El Tribunal peruano en la época de Felipe II», en J. Pérez VillanUEVA y B. Escandell Bonet (eds.), Historia de la Inquisición en España y América, Madrid, 1984, pp. 919-935, p. 926.

12. F. MARtínEZ, «Les morisques expulsés: quelques itinéraires de retours en Espagne», Actes du Xe. Congrès International d'études morisques (9-12 Mai 2001) sur Morisques, Méditerranée E Manuscrits Aljamiado, Zaghouan, 2003, pp. 133-168.

13. Ibídem, p. 166.

14. A.F. Pacca de Almeida Wright y R. Santaella Stella, Canarias y Brasil en la ruta atlántica durante la unión peninsular: 1580-1640, Canarias, 2000, p. 93.

15. B. EsCANDELl BONET, op. cit., p. 926. 
Méjico, donde entre las categorías de procesados por el Santo Oficio no son señalados los moriscos como "puntos neurálgicos"16. En el período 1571-1621, la acción inquisitorial fue dirigida contra luteranos, criptojudíos, alumbrados, bígamos, erasmistas, solicitantes, brujas y supersticiosos ${ }^{17}$.

\section{INVISIBILIDAD DEL MORISCO EN AMÉRICA}

De lo anterior podría concluirse superficialmente que acaso hubiera muy pocos moriscos en el Nuevo Mundo, si no fuera porque más de dos décadas de relevamientos sistemáticos de la presencia morisca en Sudamérica permiten afirmar lo contrario, pero debe explicarse qué hizo posible la invisibilidad del morisco en el Nuevo Mundo. Ese conjunto de causas y factores ha sido expuesto en otra obra ${ }^{18}$ y la totalidad de su desarrollo no podría repetirse aquí, pero sí vamos a enumerar por lo menos cuatro aspectos que han contribuido a enmascarar la presencia morisca en el medio hispanoamericano. Son ellos: 1) la inmigración ilegal, muy frecuente, 2) la pobreza de informes y procesos a moriscos incoados por la Inquisición novomundana; 3) el escaso número de criptomusulmanes entre los moriscos que llegaron, y 4) la falta de idoneidad de quienes debían detectar las herejías, entre las que figuraba el criptoislamismo.

Dentro del primer punto, ingresos ilegales, quedan comprendidos "náufragos, desertores y desterrados" (mía la cursiva) que "dependiendo de las condiciones de vida anterior acabaron encontrando en esas tierras un lugar de delicias" ${ }^{\prime 19}$. También fraudes de variados tipos permitieron el paso de prohibidos a las Indias, entre ellos la compraventa de licencias ${ }^{20}$ y la incuria hizo el resto ${ }^{21}$.

16. A. Huerga, «El tribunal de México en la época de Felipe II», en J. Villanueva y B. EsCANDELl Bonet (eds.), Historia de la Inquisición en España y América, Madrid, 1984, p. 937.

17. Ibídem.

18. M.E. Sagarzazu, La conquista furtiva. Argentina y los hispanoárabes, Rosario, 2001.

19. Pacca de Almeida y Santaella Stella, op. cit., p. 44.

20. R. SÁNCHEZ Rubio, La emigración extremeña al Nuevo Mundo. Exclusiones voluntarias y forzosas de un pueblo periférico del S. XVI, Madrid, 1993, p. 274.

21. Marcelino Canino da cuenta de la llegada de un morisco en un navío con registro, allí quedó apuntado el ingreso de "tres negros de Barrazas, tres negros del maestre y un moro", Documentos de la Real Hacienda de Puerto Rico. Registros de Naves. Vol. I, 1510-1519, Universidad de Puerto Rico, 1971, p. 319, apud L. LÓPEZ-BARALT y J. CAAMAÑo, «Un morisco portorriqueño, médico y alcalde de San Juan», Actes du Xe Congrés International d'études morisques sur Morisques, Méditerranée et Manuscrits Aljamiado, Zaghouan, 2003, pp. 93-109. López-Baralt acota en el artículo mencionado "ya sabemos que aunque el paso de moriscos y judeoconversos estaba prohibido, por lo dudoso de su ortodoxia, estas disposiciones se burlaron repetidamente. La presencia de descendientes de moriscos y aun de criptomusulmanes es, no cabe duda, una realidad documentada en los albores de nuestra historia nacional" (p. 94). La afirmación sirve de conclusión a una investigación sobre la existencia de otros conversos de moro, además de Ruiz, en la isla de Puerto Rico, de cuya existencia también da cuenta Luce López-Baralt en la citada comunicación (pp. 93- 95). 
Otra vía de ingreso imposible de ser detectada la proporcionaban las naves sin licencia que transportaban a quien estuviera en condiciones de pagar el traslado, fueran o no prohibidos. También una circunstancia capaz de facilitar el paso de moriscos a las colonias de América se infiere de la siguiente práctica: "las naves destinadas al Brasil y al Río de la Plata paraban en Canarias"22. Estas islas habían quedado como la única porción del territorio español de la que los moriscos no fueron expulsados ${ }^{23}$.

\section{ILICITUD Y ESCASEZ DE CONTROL GUBERNAMENTAL}

Las razones expuestas nos han llevado a proponer que para que el estudio de la presencia morisca en el Nuevo Mundo rinda frutos, conviene considerar el ingreso de moriscos -tanto como el de criptojudíos- dentro del marco amplio de acciones ilícitas en general. El ingreso de miembros de esas minorías pudo además fácilmente estar vinculado a prácticas ilegales de otra índole, sin que ello signifique que aquellas personas tuvieran particular inclinación hacia la delincuencia sino simplemente porque a ellos les estaba prohibido lo que a otros no. Por otra parte, esta vinculación o aceptación para intervenir en operaciones ilícitas no cobraría la relevancia que adquieren en el panorama americano si en la zona de nuestro estudio la clandestinidad fuera meramente residual. El caso es que, en el extremo sur de las posesiones de los Austria en América, la ilicitud configuró un fenómeno regional de grandes proporciones ${ }^{24}$, fenómeno que parece haberse estimulado durante el período de unión de las coronas de Castilla y Portugal ${ }^{25}$ por distintos motivos.

22. Pacca de Almeida y Santaella Stella, op. cit., p. 22.

23. M. Lobo CABrera, «Los moriscos de Canarias exceptuados de la expulsión», en Actes Ve. Symposium International d'Études Morisques sur: Le Vème Centenaire de la Chute de Grenade, Zaghouan, vol. I, pp. 427-442.

24. A.P. Canabrava, O Comércio Português no Rio da Prata (1580-1640), Belo Horizonte, 1984, pp. 120-123.

25. "En este contexto, es importante no perder de vista los momentos de cambio, aquellos en que el Imperio luso es aumentado y despojado de ciertas instituciones por no reflejar más la realidad o por pretender, los que las crearon o los que a ellas se sujetaban, reformar o corregir imperfecciones. Brasil bajo el Gobierno de los Felipes ilustra bien esa realidad debido a las reorientaciones españolas que cuidaban de minimizar las tendencias disgregadoras de las poblaciones lusas y el propio contrabando por ellas efectuado.

Sin embargo, es verdaderamente costosa la tarea de intentar captar momentos o tendencias de esa práctica ilícita.

Hasta los métodos más seguros de cualificación de actividades económicas pautadas en determinados sectores, en la confrontación de su resultado y en sus números elocuentes, pueden fallar como retrato fiel de la verdad. Eso se debe a la existencia de elementos cuantitativos imponderables, principalmente cuando ese contrabando se presentaba agresivo al comercio oficial. 
El escaso control por parte de las autoridades es el segundo punto a considerar como facilitador del paso de prohibidos al Nuevo Mundo, algo que ya las autoridades en su tiempo juzgaron inevitable dada "la desproporción de los medios burocráticos para cubrir el colosal tamaño del distrito peruano" ${ }^{26}$. De la misma imposibilidad se quejaron en Cartagena de Indias ${ }^{27}$, y lejos de que fuera la excepción, el mismo autor afirma que ocurría "en todas las tierras americanas" 28.

En una carta escrita por los inquisidores al Consejo se informa del ingreso clandestino de criptojudíos "particularmente por el puerto de buenos ayres... y se vienen por tierra al Pirú, a Potosí, La Plata y otras partes del Reyno, y lo mesmo sucede por los puertos de Veneçuela, laguna de maracaybo, sancta martha y cartagena... que los mas guardan la ley de Moysen" ${ }^{29}$.

El tercer punto y el cuarto están interrelacionados. Por un lado, deducimos que pocos moriscos interesados en mantener su religión y sus costumbres dejarían España para venir a una colonia donde teóricamente les esperaban las mismas leyes y el mismo trato que en su patria. En todo caso, América ejercería su atracción sobre aquellos mejor cristianizados, que a pesar de ello comprendían que descender de moros les impedía integrarse y ascender socialmente. Para este tipo de morisco, un cambio de escenario era todo lo que hacía falta para borrar el origen. En las colonias, esa posibilidad estaba asegurada, entre otras razones por la escasa idoneidad de los agentes encargados de descubrir al cristiano nuevo de moros o de judíos. No sería fácil detectar a conversos que físicamente no se diferenciaban de los españoles cristianos viejos sino en la negativa a consumir carne porcina, hecho que tenía lugar en la intimidad del hogar. Asimismo, el tipo de vida de muchos de los primeros españoles, al unirse a mujeres indígenas, fue rural, lo que a propósito de las costumbres les favorecía triplemente. Porque dentro del matrimonio era entonces el varón (un morisco, en este caso) el que a través de su supremacía como conquistador y como varón imponía su voluntad y sus costumbres, y porque el alejamiento de los centros urbanos le permitía reproducir sin testigos las tradiciones que traía.

Por considerables motivos semejantes a los de las situaciones anteriormente descritas, en que son presentados hechos de naturaleza diversa pero de estructura semejante, no es posible percibir una sola línea de conducta válida para todo el esquema de acción y tranquilidad de la mentalidad colonial sobre las actividades mercantiles entre las principales zonas del contrabando americano, incluyéndose ahí Canarias, las islas portuguesas, Brasil y el Plata.

Razones también semejantes en estructura, si no en naturaleza, a las de las situaciones antes comentadas, podrían incurrir en el gravísimo riesgo de ignorar hechos esenciales a la apreciación de la realidad histórica..." (PACCA DE AlmeIDA y SANTAELla STElla, op. cit., pp. 56-57).

26. ESCANDELL BONET, op. cit., p. 926.

27. M. TejAdo FernáNDEZ, «El apogeo del Santo Oficio (1569-1621)», en J. Pérez VillanUeVA y B. EsCANDell Bonet (eds.), Historia de la Inquisición en España y América, Madrid, 1984, p. 989.

28. Ibídem.

29. EsCANDELl BONET, op. cit., p. 929. 
Por otra parte, aquella razón que daban los obispos, de no poder llegar a los pobladores porque estaban diseminados en territorios demasiado extensos, conspiró también contra la autoridad inquisitorial encargada de detectar criptomusulmanes, si los había.

Insistimos, no obstante, en la asimilación de los moriscos como rasgo presente entre los interesados en pasar a las Indias ya que allí podría estar la razón por la que las autoridades no los hubieran considerado "puntos neurálgicos". Así las cosas, está claro que estas personas no presentaban un peligro capaz de atraer la atención del apocado Santo Oficio americano. ¿Por qué motivo habría de perseguirse a gente humilde que vivía lejos de todo y que quizá lo último que los vinculara al pasado islámico fuera el rechazo a la carne de cerdo, que nadie podía comprobar? En cualquier caso, esta suma de circunstancias consideradas desde la perspectiva de los moriscos configuraba un escenario ventajoso para su radicación, especialmente accesible a los que quedaron viviendo en las Canarias.

\section{ILEGALES Y MORISCOS EN AMÉRICA}

Era posible llegar ocasionalmente en naves legales, o hacerlo ilegalmente, como lo hizo el portugués Cristóbal Ataide, residente de Santa Fe la Vieja en el siglo $\mathrm{XVI}^{30}$, de cuya existencia sabemos precisamente por haberse radicado en una ciudad de cierta importancia para los parámetros urbanos del Río de la Plata a fines del siglo XVI. Si en vez de eso Ataide se hubiera internado en el campo, posiblemente nunca habríamos conocido su historia ni tampoco habría tenido que dar cuentas a un oficial de justicia sobre su origen y presencia en América. Sabemos que tras recibir una advertencia se le concedió un permiso de residencia por haber alegado ser padre de un sacerdote.

También el caso del morisco estudiado por Luce López Baralt y Josué Caamaño quedó registrado por tratarse nada menos que del licenciado Ruiz, médico que llega a ser alcalde de San Juan de Puerto Rico, algo que no solamente transgredía la prohibición de ir a América sino otra, porque el ejercicio de una profesión liberal estaba igualmente vedado a los de sangre impura. Por otra parte, con solo declarar Ruiz que era oriundo de Magacela, Extremadura, había dicho suficiente. Cuando entre 1570 y 1574 recibió Extremadura su cuota de once mil moriscos expatriados de Granada, las villas de Magacela y Benquerencia quedaron exentas de recibirlos en calidad de vecinos "por poseer ya un elevado número de moriscos" ${ }^{31}$. En 1584, según palabras del visitador Frey Antonio Rodríguez de Ledesma, "en la dicha villa de Magacela, que es toda de

30. SAgarZAZU, op. cit., p. 208.

31. B. MiRANDA DíAz, Reprobación y persecución de las costumbres moriscas: el caso de Magacela, Badajoz, 2005, p. 100. 
moriscos, fuy ynformado y averigüé que no resçebían el santísimo sacramento más que uno o dos de los dichos moriscos lo cual a sido y es de tan mal ejemplo que conviene que su magestad mande poner en ello el remedio que conuiene para que se escuse tanto mal y biuan cristianamente" ${ }^{\prime 32}$.

Los inconvenientes de todo tipo con que se encontró el Santo Oficio para llevar adelante las tareas y controles para los que había sido creado no fueron, como se vio, prerrogativa de sus tribunales novomundanos, si bien es la actuación de estos lo que ahora nos interesa. Y nos interesa porque estamos tratando de unir cabos sueltos del pasado morisco en América con la ayuda de baquiano, voz que informa de la existencia de hombres venidos de España, bien arraigados a su nueva tierra pero que no se comportan como los demás españoles de distinto oficio que cumplen tareas varias en las villas o en las instituciones coloniales. Quisimos averiguar por qué.

Mientras desde Puerto Rico se da cuenta de "el descuido y la irregularidad del funcionamiento del Santo Oficio en la isla a lo largo del siglo XVI" 33 , la instalación del tribunal en Cartagena de Indias ${ }^{34}$ tropieza desde el principio con un conjunto de obstáculos que se repetía en las demás sedes de la Inquisición novomundana. Una de las dificultades mayores "fue la escasez de personal, que contrastaba con la extensión territorial de su distrito [...] En efecto, contaba con dos oidores... uno en Santa Fe y otro en Santo Domingo [...] En cuanto a los familiares, la escasez no podía ser más agobiante; en el lugar de asiento del Tribunal debía haber doce pero solamente estaban nombrados cinco" ${ }^{\prime 35}$.

Todos estos inconvenientes explican por qué la marginalidad podía prosperar en las Indias con facilidad, y es ese el motivo por el que la clandestinidad ofrece un marco adecuado para percibir una presencia tan esquiva como la morisca en América. La ausencia de controles institucionales favoreció un estado de cosas que sería aprovechado por quienes buscaban la grieta para escapar de una situación agobiante, y en esas circunstancias se encontraban los miembros de las minorías marginalizadas de la sociedad española.

\section{DONDE SE ESFUMAN LAS FRONTERAS}

Por otra parte, la vida en América tuvo que ser, desde sus inicios, muy distinta de la que llevaban los españoles en la metrópoli. Las riquezas del Nuevo

32. Documento conteniendo la Visitación de frey Antonio Rodríguez de Ledesma al Partido de La Serena, apud Miranda DÍAZ, op. cit., p. 101.

33. López-BARALt y CAAMAÑo, op. cit., p. 95.

34. J.T. Medina, Historia del Tribunal del Santo Oficio de la Inquisición de Cartagena de Indias, Santiago de Chile, 1899, pp. 114-115.

35. Tejado FernándeZ, op. cit., p. 994. 
Mundo produjeron rápidos cambios sociales e individuales que "irían, incluso, a crear nuevos valores dentro de los eslabones religiosos, llegando al punto de permitir que ciertas instituciones, en otros lugares vigorosas y dinámicas, fuesen alcanzadas en su esencia, como ocurrió más tarde con la del Santo Oficio en Brasil" ${ }^{36}$. Señalan asimismo que "Es posible que ese Tribunal hubiese desempeñado hasta la función de encubrir cristianos nuevos en la Colonia, sirviéndoles de vehículo de ascensión social. Para eliminar los rasgos sospechosos del origen de la fortuna, el hombre rico intentaba la búsqueda de la distinción religiosa en la más prestigiosa de las compañías, inclusive entre los distintos familiares del Santo Oficio en Brasil" ${ }^{37}$.

Todos estos factores combinados convergen para generar una imagen de algunos primitivos pobladores venidos del otro lado del Atlántico que coincide con lo que viene sosteniendo desde antaño la tradición popular en América: que los primeros colonos no eran gente de buena estirpe, lo que ha recibido el valiente descrédito, entre otros, del historiador Guillermo Furlong ${ }^{38}$, preocupado por atribuirle a los futuros argentinos y sus vecinos un origen menos indigno. El padre Furlong, sin demorarse en demasiadas pruebas, sostiene que no es cierto que muchos antepasados de los criollos hayan purgado sentencias en prisiones peninsulares, y aunque no lo explicita, parece entender que quienes poblaban las cárceles españolas serían siempre delincuentes, sin mencionar de qué delitos se trataba $u$ otros motivos ajenos al delito por los que se puede perder también la libertad. Por ese razonamiento se deja de ver justamente la causa por la que los moriscos conocieron las prisiones inquisitoriales y la dudosa fama que podía acompañarles en América, donde nunca quedó claro quiénes habían sido los moros allá en España.

La sociedad americana, a diferencia de la peninsular, creció sin que llegara a la mayoría un perfil nítido del morisco; nunca se aclaró en estas latitudes que un sector de la sociedad española había sido musulmán; posiblemente fue algo más conocido el caso de los judíos. De todas maneras, no es razonable conjeturar que las autoridades coloniales fueran a dar explicaciones a propósito de la minoría morisca y su situación contemporánea, lo que significó un silencio total a propósito de los moriscos en el medio americano. La Iglesia era la encargada de trabajar por la unidad confesional de todos los súbditos de la Corona española, y la Inquisición de encausarlos si había dudas, quejas o delaciones sobre la conducta de los pobladores, pero la realidad morisca, el pasado que unos y otros querían dejar atrás, no tuvo por qué constituir una cuestión preocupante para ninguna de las partes involucradas en una disputa que jamás fue sino residual en América.

36. Pacca de Almeida y Santaella Stella, op. cit., p. 49.

37. Ibídem.

38. G. Furlong CARdif, Historia social y cultural del Río de la Plata (1536-1810), Buenos Aires, 1969, p. 1. 
Esta indiferencia frente al problema morisco en el Nuevo Mundo no debe interpretarse como resultado de una ausencia total de descendientes de aquella comunidad. Tampoco como que la sociedad colonial hubiera cambiado de código al extremo de equiparar socialmente a cristianos viejos y conversos. El comportamiento menos persecutorio de las autoridades en América hacia los descendientes de moros se entiende como parte de un expreso mandato de la Corona, y por el ajuste a las nuevas condiciones de vida que los venidos de España, en su conjunto, debían enfrentar en el Nuevo Mundo. Frente a las costumbres completamente desconocidas que volcaba la vertiente indígena -y también los negros- en la sociedad colonial, los conversos eran apenas otro modo de ser hispánico que hacían que las diferencias entre ellos y los cristianos perdieran volumen y prioridad. Este nuevo diseño social, donde los conversos dejaban de ser el grupo hostil, sería un importante paso hacia la confusión de raíces que impediría en adelante a los criollos descendientes de moriscos comprender o recordar su origen. Claro que, en el caso de que individualmente hubieran llegado a recuperar la memoria de su origen, tampoco podían publicarlo, pues descender de conversos no solo infamaba sino que, al estar prohibida su residencia en las Indias, era dato que incriminaba instantáneamente.

Desde la perspectiva del morisco, la imposibilidad de revelar el origen en el Nuevo Mundo hizo que sus propios hijos ignoraran los vínculos que los unían a sus antepasados en España, con lo que pasaría al olvido toda la historia de la adscripción al islam y su posterior ilegalización. Pero, desde la perspectiva cristianovieja, si bien en América la inquina contra los conversos no alcanza la gravedad que suele tener en España, sí se trasladó la conciencia de quién es quién, motivo por el que el patriciado mantuvo distancia frente a los conversos.

Otro aspecto negativo del quién es quién quedaría reflejado en que, al momento de cuajar la separación de clases, los miembros de la clase baja hispánica quedarían difusamente asociados a una condición moral dudosa. Es esa sospecha la que el padre Furlong quiere desactivar, dignificando a quienes, sin embargo, las propias autoridades seguían viendo como próximos al delito por su propio origen, y sin que la ilicitud en cuestión fuera resultado de otra cosa que de la adscripción a una comunidad marginalizada por motivos religiosos y políticos.

El término cafre resume localmente lo que podría reflejar el origen de la base popular argentina. ¿Qué es un cafre sino un cualquiera, de baja cuna? Pero lo que cafre encierra en su étimo árabe es el motivo por el que la cuna no es buena: cafre es un infiel. Cafre en su raíz conserva la memoria islámica de desvalorizar al otro por no ser de la misma fe. Desde el punto de vista del descendiente de moriscos, cafre sería el indio, pero para las autoridades, cafres eran los españoles de la otra vereda, los ex infieles. ¿Y quiénes fueron los últimos sospechados de infidelidad en la España que ya había expulsado a los judíos? Los moriscos y sus descendientes. 


\section{LA COYUNTURA TAMBIÉN EN EL LARGO PLAZO}

El sentido de la coyuntura es fundamental para comprender los caminos seguidos por los moriscos cuando se les cancela la posibilidad de ser miembros de su colectivo, que hace que la comunidad originaria deje de servirles de referente y refugio.

La deslegitimación del colectivo trajo como consecuencia sumir a los moriscos en una dudosa condición que les permitía continuar siendo españoles al tiempo que les exigía dejar de ser musulmanes. En esto último, sin embargo, descansaba la identidad de un morisco, de modo que el haber recibido el bautismo, sin desearlo, nunca pudo convertirlo en el cristiano que exteriormente debía ser.

El morisco cristianizado no pudo menos que ser un individuo desdoblado, uno por dentro, otro por fuera. Ahora bien, ¿no es esta condición, de reunir en uno mismo, un ser y un parecer que no conjugan, la que obliga a conductas ladinas? Por ese camino, ladino llega a ser un verdadero sambenito social que resume en el Río de la Plata la conducta de aquél en quien no se debe confiar, porque no es lo que parece.

La tacha social que suponía llevar sangre prohibida bien pudo dejar en sus descendientes conversos características que la mayoría de los españoles de origen cristiano acabaron resumiendo en el infamante ladino que cumple en América la función denigradora que el origen ya no puede hacerlo porque se había perdido rastro de él, o mejor dicho, memoria de él. Si un capitán no sabe a quién transporta en su navío ${ }^{39}$, si el registro de pasajeros a Indias omite nombres ¿quién podía señalar con certeza a un morisco en las colonias? ${ }^{40}$.

Pero frente a este anonimato étnico, en la Argentina ha sido una constante atribuir, por un lado, un origen humilde, cuando no rayano en la marginalidad, a la primitiva población de origen hispánico, y a la vez, destacar la nobleza y dignidad del criollo nacido de esa misma gente. Aunque un pasado libre de tachas pudo figurar entre las preocupaciones de los individuos comprometidos con el proceso independentista, no hubo aquí fuerte hincapié en la limpieza de sangre, como se encargaría de reflejar, ya en plena madurez republicana, el dicho popular "todos venimos... de los barcos". Sobre este interrogante como telón de fondo, proyectaría ocasionalmente su sombra la idea subyacente de un origen dudoso.

39. "El dicho licenciado Ruiz vino sin lisençia y ascondidamente" declaró Pedro de Riasa, testigo de Ponce de León en la causa criminal iniciada por Ruiz contra el anterior (AGI, Justicia 979, folio 10v.12). Otro testigo, Tomé Lépez agrega: "Y sabe este testigo que vino por via de las yslas porque este testigo lo vio embarcar en la palma", apud LÓPEZ-BARALT y CAAMAÑO, op. cit., pp. 101-102.

40. Sólo los avisados sabían que venir de "las yslas" (Canarias) e ingresar indocumentado era casi sinónimo de converso. 
Toda esta cuestión, a nuestro juicio, es resultado de la supervivencia del marco ideológico de las propias autoridades coloniales españolas, que procedían o estaban aliadas al sector que detentaba el poder, los cristianos viejos. Estos funcionarios no podían ver con buenos ojos la presencia de esos otros españoles que emigraban de España. Tampoco podían identificarlos con certeza puesto que llegaban con nombres cristianos y luego de cumplir con los requisitos de limpieza de sangre, algo que no debe confundirse con no llevar efectivamente sangre prohibida, pues también estos certificados se falsificaban.

En América, los desposeídos de vieja data, los peones, la gente sin propiedades -sin bienes ni raíces, valga el juego de palabras-constituye la cantera donde hallar a los descendientes de moriscos, toda vez que el rechazo religioso asume, en las colonias, la forma de desposeimiento material y ausencia de pasado. Y esas mismas condiciones reiteradas a lo largo de siglos acabarían construyendo la mentalidad propia de un grupo particular, compuesto por peones, gauchos y trabajadores rurales, gente de escasos recursos y excluidos casi siempre de las posibilidades de ascenso social. Dentro de este grupo se encuentra el baquiano.

El baquiano desempeña tareas aprendidas de manera práctica; un refrán local dice "para hacerse baquiano hay que perderse alguna vez".

A medida de que fueron ingresando las camadas de nuevos colonizadores, encontraron a otros que les habían precedido, bien afincados pero sin más capital que el conocimiento de la tierra, conocimiento que el baquiano no podía utilizar en beneficio propio, pues nunca fue -ni es- terrateniente. Son los terratenientes los que comenzarán a emplear a los baquianos como peones.

Cabe preguntarse por qué el baquiano no es dueño de la tierra que conoce mejor que su patrón. En la respuesta intervienen las disposiciones de la legislación colonial. El reparto de la tierra conquistada era resorte de la autoridad colonial, del gobierno, fundamentalmente en manos de cristianos viejos. Era adjudicada en forma gratuita como pago de servicios y favores a la Corona, motivo por el que iba a parar a manos de gente de cierta alcurnia. El baquiano, por el contrario, fue siempre un sujeto sin contactos en el funcionariado, ajeno al mundo oficial y a los estamentos superiores de la sociedad colonial. Era, sigue siendo, un hombre de campo alejado de las autoridades y quizá poco afecto a ellas en el pasado, cuando se sentía más seguro viviendo perdido en una estancia que en la ciudad, "símbolo del dominio hispano y del triunfo del Cristianismo" ${ }^{\prime 41}$ y donde podía ser observado por vecinos de otras costumbres, o llamar la atención de allegados a la Iglesia, la Curia o a la Inquisición.

El perfil económico y social del baquiano era el de un desheredado, circunstancia que comparte con el morisco peninsular. El parentesco se refuerza

41. Domínguez Ortiz, op. cit., p. 34. 
al destacar que, en los territorios rioplatenses, este ejemplar social conserva la tradición semita de no consumir carne porcina. El rechazo al cerdo quedaría como la señal de adscripción al Islam por antonomasia ${ }^{42}$, y a ella se apegaron con firmeza los moriscos. De modo que la existencia de igual práctica en suelo americano no puede adjudicarse a los cristianos viejos, sino a los moriscos, no sin considerar que podría haberse acentuado con el ingreso de portugueses criptojudíos, agentes activos del comercio atlántico y presentes en la ruta del contrabando ${ }^{43}$. Con todo, los criptojudíos pertenecían a una clase social distinta de aquella que proveía de peones a las estancias. (Los alcances y significados del tabú porcino descritos en otra ocasión ${ }^{44}$ no van a reiterarse ahora.)

En América, como viene sucediendo con los territorios conquistados en cualquier lugar, las autoridades adjudicaron la tierra a quien les convenía, y aquí fue a miembros del mismo sector étnico-religioso que detentaba el poder, lo que dejaría a los cristianos nuevos fuera de su posesión. Pero no de explorarla y conocerla.

El empleo de una raíz árabe podría indicar que, entre quienes componían la peonada colonial, fueran o no baquianos, abundaba gente con un léxico particular, diferenciado del de sus primeros patrones godos y todavía en condiciones de crear algún término sobre étimos no siempre de origen latino. Porque pasa lo mismo con argelar, una voz desconocida en España que significa fastidiar y procede del árabe ar-riŷl, el pie, por extensión también una enfermedad del vaso de los caballos que los pone molestos ${ }^{45}$.

Lo que estamos sugiriendo es que los introductores de baquiano podrían haber sido peninsulares que no hubiesen perdido totalmente el contacto con su primitiva lengua, aunque hiciera variable tiempo que la hubiesen abandonado, según vinieran de Castilla, de Aragón, de Valencia, o de Magacela ${ }^{46}$. Para principios del siglo XVII, los dos primeros grupos hablaban en general bien el castellano ${ }^{47}$, si bien la nota número 46 está ahí para recordar que no faltaron excepciones. Lo que no sabemos es cuántas excepciones más tuvieron lugar y, lo que también hemos querido destacar en este trabajo, si son ciertas las características de la colonización cisplatina entre las que figura la facilidad para el

42. M. García Arenal, Inquisición y Moriscos: los moriscos del tribunal de Cuenca, Madrid, 1978, p. 69.

43. J.A. TobíAs, História das Idéias no Brasil, Saõ Paulo, 1987, pp. 38-39.

44. En SAGARZAZU, op. cit.

45. SAGARZAZU, op. cit., p. 162.

46. El conde de Salazar, encargado de expulsar a los moriscos de ese sitio, le escribe al rey en 1610, "Benquerencia y Magacela, dos lugares todos de moriscos... aquy cesa el ynconveyente que podya tener el echar los antyguos por estar casados con cristiano byejos, qe en esto lugares no ay ninguno, ny onbre que se pueda dudar de que es morysco en todo esto". A.G.S., Secretaría de Estado, Leg. 235, apud Miranda DíAZ, op. cit., p. 116.

47. L.F. BERNABÉ PONS, «L'écrivain morisque Hispano-Tunisien Ibrahim Taybili. Introduction a une littérature morisque en Tunisie», en Mélanges d'archéologie, d'épigraphie et d'histoire offerts á Slimane Mustapha Zbiss, Tunis, 2001, pp. 255-256. 
ingreso de prohibidos, lo que a su vez daría más oportunidad de que se plasmaran otras conductas particulares, más laxas, a medida de que la colonización se aleja en la geografía y el tiempo, de los grandes ejes de Méjico y Perú, donde tuvieron lugar comportamientos más duros y pragmáticos o rapaces, por la presencia de riquezas fácilmente explotables.

Pero, sobre todo en lo tocante a la lengua, el arraigo afectivo a ella cuenta, y es lo que hace que sus hablantes conserven giros o voces a veces sueltas por mucho tiempo aunque ya no se comuniquen a diario en ella. Es lo que ha sucedido con el castellano de los descendientes de moriscos radicados en Túnez ${ }^{48}$, quienes con el afán de conservar una identidad cultural distinta de la local, recurrieron al empleo esporádico de voces hispánicas cuando el español ya no era de uso cotidiano. El mismo tipo de fenómeno, pero al revés -empleo de voces árabes en el castellano- podría explicar la presencia de estos arabismos en suelo sudamericano, arabismos que aparecen relacionados a las ocupaciones por excelencia de los moriscos en América, tareas rurales, especialmente de arriería, medio en que perviven por igual argelado y baquiano, tal como en Túnez el léxico hispánico sobrevivió en voces asociadas a una ocupación característica de los moriscos, la fabricación del bonete de fieltro.

Merece atención otro aspecto de baquiano, la confusión ortográfica que a menudo suscita incluso entre personas ilustradas, porque cuando eso sucede, es señal de desorientación lingüística. No es raro verlo escrito vaqueano, por asociación con vacuno, tipo de ganado que conforma el grueso de la ganadería argentina. Otra elocuente curiosidad es que la voz carece de alcurnia, algo ha hecho que se la soslayara allá donde la necesitaban, en el ejército, por ejemplo (y la cursiva que sigue es mía): "En los ejércitos regulares los baquianos se alistaban en una unidad denominada compañía de guías, agregada a los servicios del cuartel general" ${ }^{49}$. Un argentino estándar jamás diría guía, salvo que hable de turismo, u otra aplicación moderna. El término habitual es baquiano, pero por esas cosas que cuestan desentrañar, el Ejército evitó consignarlo por escrito.

La ganadería en Argentina sigue tradicionalmente empeñada en la cría de bovinos y, en menor medida, de ganado lanar. En ese esquema no es secundario señalar que el gaucho, mano de obra por excelencia en ese medio, rehúye la cría del cerdo: sencillamente no lo hace. Este animal que consumían los cristianos viejos, se conservó allá donde los cuidadores, los peones, tenían origen indígena, como sucede en la zona andina, pero desaparece de las grandes estancias donde el trabajo queda a cargo de criollos de origen peninsular. Así ocurrió en la cuenca cisplatina, desde Rio Grande do Sul hasta el sur pampeano. Y así desapareció prácticamente el cerdo de la mesa argentina, al punto de perderse a nivel popular el tocino. Esa preparación vuelve al léxico argentino -más que

48. Ibídem, p. 257.

49. J.M. SAROBE, «El gaucho guerrero», en G. TABOADA (ant.), Gauchos, Buenos Aires, 1992, p. 264. 
a la gastronomía- con los inmigrantes italianos del siglo XIX, como lo refleja la denominación vigente: el italianismo panceta.

Los criollos de las colonias no tuvieron conciencia de haram, porque tampoco serían musulmanes, sino más bien descendientes de conversos, según denotan estos rasgos que apuntan a una arabidad que sobrevive a una desislamización del acervo moro. Pero la contaminación con vaca sufrido por baquiano acaba añadiendo una última connotación indirectamente relacionada al tabú islámico.

A manera de conclusión y como señala Bernabé Pons ${ }^{50}$ : “Empieza a ser un lugar clásico en la historiografía referida a los moriscos el hacer notar que existe una enorme diferencia entre la atención prestada a éstos mientras permanecieron en el territorio peninsular y la que han merecido una vez que abandonan España". Cabe agregar que esta merma de atención, sin embargo, todavía hace referencia a los estudios realizados sobre los moriscos radicados en el Magreb y Turquía, y es una situación privilegiada si la comparamos con lo que ocurre con los vestigios moriscos en América, donde la tarea pendiente es grande, sin conseguir la debida atención académica ni una apropiada cobertura institucional.

\section{RESUMEN}

La voz baquiano, muy difundida en el Río de la Plata y también en Venezuela desde los inicios de la colonización hispánica, se halla construida sobre un étimo árabe y ha permanecido ausente del castellano de España. El presente trabajo relaciona la implantación y vigencia del término en los territorios coloniales a la presencia de moriscos a los que, si bien la legislación prohibía el ingreso, hay documentos que prueban su presencia, como así también razonables indicios de entradas clandestinas. Destacamos el origen y extensión del uso de baquiano en relación a su portador habitual en Argentina, que suele ser un gaucho, en quien otras pautas de filiación hispanoárabe habían sido ya detectadas.

Palabras clave: moriscos, Argentina, terminología árabe, gaucho.

\section{ABSTRACT}

Baquiano has been a well established word in the language of the River Plate and Venezuela since the begining of the Spanish colonisation. The term

50. L.F. BERnABÉ PONS, «Las emigraciones moriscas al Magreb: balance bibliográfico y perspectivas», en Relaciones hispano-marroquies: una vecindad en construcción, edición a cargo de A. Planet y F. Ramos, Madrid, 2006, p. 63. 
evolves from an Arab stem and has remained unknown to Spanish speakers within Spain. This paper aims at connecting the spreading of such a word in South America, to Spanish Moriscos, for in spite of the ban on ex members of the Spanish Muslim community to inmigrate to colonial territories, documents endorse their presence, while ilegal entries seem to stand behind the even larger cultural heritage bearing their imprint, too. We also underline the conection between this local use of baquiano and the gaucho, his culture bearing further signs of Hispanoarabic coinage as well.

Key words: moriscos, Argentina, arabic terminology, gaucho. 